\title{
Factors influencing self-sealing of sclerotomy performed under gas tamponade in 23-gauge transconjunctival sutureless vitrectomy
}

This article was published in the following Dove Press journal:

Clinical Ophthalmology

10 October 2014

Number of times this article has been viewed

\author{
Hirotsugu Takashina ${ }^{1,2}$ \\ Akira Watanabe ${ }^{2}$ \\ Katsuya Mitooka ${ }^{1,2}$ \\ Hiroshi Tsuneoka ${ }^{2}$ \\ 'Department of Ophthalmology, \\ Jikei University School of Medicine \\ Daisan Hospital, ${ }^{2}$ Department of \\ Ophthalmology, Jikei University \\ School of Medicine, Tokyo, Japan
}

Correspondence: Hirotsugu Takashina Department of Ophthalmology, Jikei University School of Medicine, 3-19-18 Nishi-shinbashi, Minato-ku, Tokyo 105-847I, Japan

Tel +8I33433 IIII extension 358 I

Email two-shina@s7.dion.ne.jp
Background: The purpose of this study was to investigate factors influencing self-sealing of sclerotomy performed under gas tamponade in 23-gauge transconjunctival sutureless vitrectomy.

Methods: This study was a retrospective review of 84 patients ( 84 eyes) who underwent 23 -gauge transconjunctival sutureless vitrectomy under gas tamponade by a single surgeon. At the end of surgery, the sclerotomy was massaged to promote self-sealing. Factors influencing massage time were examined using multiple regression analysis. Independent variables were age, surgical time, vitreous incarceration, intraocular manipulation, and axial length.

Results: Significant factors were intraocular manipulation and vitreous incarceration in the examination of all sclerotomies, age only in the examination of infusion sites, and vitreous incarceration only in the examination of manipulation sites.

Conclusion: In sclerotomy performed with gas tamponade using 23-gauge transconjunctival sutureless vitrectomy, intraocular manipulation influenced self-sealing of sclerotomy the most, followed by vitreous incarceration, and then age.

Keywords: sclerotomy, gas tamponade, 23-gauge, transconjunctival sutureless vitrectomy, self-sealing

\section{Introduction}

Fujii et al first reported 25-gauge transconjunctival sutureless vitrectomy (TSV) in $2002,{ }^{1}$ and Eckardt reported 23 -gauge TSV in $2005 .^{2}$ The characteristic procedure in TSV compared with conventional 20-gauge vitrectomy is sutureless sclerotomy; in other words, self-sealing sclerotomy. Potential advantages of self-sealing sclerotomy in TSV over conventional 20-gauge vitrectomy are faster wound healing, reduced conjunctival scarring, greater patient comfort, decreased postoperative inflammation, less postoperative astigmatic change, and shorter surgical opening and closing times. ${ }^{3}$

Although various vitreoretinal diseases have been treated using TSV, complications of sclerotomy such as leakage and postoperative hypotony remain. Incomplete wound apposition leads to postoperative hypotony, a known risk factor for the development of acute-onset endophthalmitis after TSV. ${ }^{4}$ Furthermore, in cases of gas tamponade in the vitreous cavity, postoperative gas leakage from sclerotomy may influence the success of surgery because of insufficient gas tamponade. A positive self-sealing sclerotomy technique is thus required.

Lin et al stated that use of an oblique sclerotomy incision compared with a conventional sclerotomy incision reduced the incidence of postoperative leakage from sclerotomy because of its self-sealing effect, ${ }^{5}$ and Shimozono et al found that 
a three-step incision, like the self-sealing incision in cataract surgery, reduced postoperative hypotony. ${ }^{6}$ Such findings suggest that restoring the valve architecture of sclerotomy, ie, mechanical adherence between the internal and external valves, promotes self-sealing. On the other hand, Amato et al described leakage-related complications, particularly in previously vitrectomized eyes, due to the failure of peripheral vitreous to plug the unsutured sclerotomy. ${ }^{7}$ The mechanisms behind self-sealing in sclerotomy thus appear to involve restoration of the valve architecture and vitreous incarceration. However, statistical analysis of the factors influencing selfsealing in sclerotomy has not yet been reported. The present study statistically examined factors influencing self-sealing of sclerotomy in gas-exchanged eyes using 23-gauge TSV.

\section{Patients and methods}

This study involved a retrospective review of cases in which 23-gauge TSV was performed. We enrolled 84 patients (84 eyes) who underwent 23-gauge TSV at Jikei University School of Medicine Daisan Hospital in Tokyo, Japan, from December 2010 through December 2011. No patient had any history of prior retinal detachment surgery or vitrectomy for other ocular disease. The study was approved by the ethics committee of Jikei University. The potential benefits of the technique, along with possible risks, were explained to the patients, and informed consent was obtained in accordance with the Declaration of Helsinki. Surgery was performed for 36 consecutive patients with primary rhegmatogenous retinal detachment and 48 consecutive patients with macular disease (idiopathic epiretinal membrane or idiopathic macula hole). All surgeries were performed by a single surgeon (HT).

For each patient, we made oblique incisions vertical to the limbus at an angle of $45^{\circ}$ to the sclera with a two-step technique, first making a tunnel incision through the conjunctiva and sclera, then inserting the microcannula in the inferotemporal, superonasal, and superotemporal quadrants, using a 23-gauge system (Dutch Ophthalmic Research Center, Zuidland, the Netherlands) and a 24-gauge microvitreoretinal blade (Mani, Tochigi, Japan). All cannula were placed $4.0 \mathrm{~mm}$ posterior to the limbus in phakic eyes and $3.5 \mathrm{~mm}$ posterior to the limbus in pseudophakic eyes. Inferotemporal sclerotomy was used for intraocular infusion (infusion site); superonasal and superotemporal sclerotomies were used for intraocular manipulation, such as using a pneumatic vitreous cutter, endolaser probe, and endoilluminator (manipulation sites). No surgeries used a wide-angle viewing system or perfluorocarbon. Peripheral vitrectomy and confirmation of the amount of remnant vitreous were performed with scleral depression. The methods for peripheral vitrectomy differed between the two disease types. In the case of rhegmatogenous retinal detachment, thorough peripheral vitrectomy was performed to prevent relapse. This procedure was regarded as involving less vitreous incarceration by remnant vitreous. In the case of macular disease, minimal peripheral vitrectomy was performed to minimize operative invasion. This procedure was regarded as causing vitreous incarceration by remnant vitreous. Since leaving the vitreous with air-fill at the end of surgery to prevent leakage and vitreous tractionrelated complications may also be helpful for self-sealing of the sclerotomy, ${ }^{7,8}$ exchange of intraocular fluid for gas was performed in all cases in this study to prevent leakage from the sclerotomy. In cases of rhegmatogenous retinal detachment, subretinal fluid was drained using a head-tilt technique or drainage retinotomy as much as possible. The amount of intraocular gas differed between the two disease types. Total fluid-air exchange was performed in cases of rhegmatogenous retinal detachment and macular hole, and partial fluid-air exchange (approximately $1.5 \mathrm{~mL}$ ) was performed to covering sclerotomies in a supine position in cases of epiretinal membrane. Afterwards, the cannula was removed from each sclerotomy (first from the manipulation site on the left side, then from the manipulation site on the right side, and finally from the infusion site), and a cotton swab was rolled and massaged over each sclerotomy to promote reliable self-sealing. If a sclerotomy was found to be leaking or a leak was suspected on direct observation despite scleral massage for up to about a few minutes, a suture was placed to close the sclerotomy. Self-sealing of sclerotomy was defined as no leakage at a pressure of $30 \mathrm{mmHg}$ using a CV24000 system (Nidek, Aichi, Japan), or no leakage at a pressure of approximately $30 \mathrm{mmHg}$ with palpation using gas injection via the pars plana. At the end of surgery, cases of rhegmatogenous retinal detachment and macular hole underwent $20 \%$ sulfur hexafluoride gas exchange completely by injection via the pars plana. Scleral buckling was not performed in any case. Patients with rhegmatogenous retinal detachment and macular hole were required to remain in a face-down position for several days after surgery, and patients with epiretinal membrane were required to stay in a face-up position to cover sclerotomies with air for several hours after surgery.

Parolini et al noted that sutures might have been avoided by prolonging sclerotomy massage. ${ }^{9}$ Massage time, the period of scleral massage for self-sealing at each sclerotomy, was therefore interpreted as reflecting the degree of difficulty of self-sealing in this study. Factors influencing massage time 
were examined with multiple regression analysis, in all sclerotomies, in infusion sites, and in manipulation sites. An $F$-value over 2 and a $P$-value less than 0.05 was considered significant for analysis. In the analysis of all sclerotomies, the criterion variable was massage time, and the independent variables were age, surgical time, vitreous incarceration, intraocular manipulation, and axial length. Massage time and surgical time were measured from a video recording of the surgery. Surgical time was defined as the period from cannula insertion to cannula removal, and intraocular manipulation was defined as movement of aiming intraocular instruments, such as the pneumatic vitreous cutter, endolaser, and endoilluminator, at multiple directions of the vitreous cavity. This is because the influence of intraocular manipulation exists at manipulation sites, but is greatly reduced at infusion sites. In the analyses of infusion sites only and of manipulation sites only, the criterion variable was massage time, and the independent variables were age, surgical time, vitreous incarceration, and axial length.

\section{Results}

Baseline features in the cases of rhegmatogenous retinal detachment and in the cases of macular disease (massage time at infusion sites, massage time at manipulation sites, total massage time of each case, age, surgical time, axial length) are summarized in Tables 1 and 2. Six sclerotomies, all in cases of rhegmatogenous retinal detachment, required suture placement at the end of surgery, and mean massage time for these sclerotomies was 237.0 seconds. Mean massage time in sclerotomies that appeared self-sealed at the end of surgery was 100.5 seconds in cases of rhegmatogenous retinal detachment. On the other hand, no sclerotomies required suture placement in the case of macular disease, and mean massage time in these cases was 55.0 seconds.

The statistical data are summarized in Tables 3-5. In the analysis of all sclerotomies $(\mathrm{n}=252)$, intraocular manipulation $(F=29.8, P<0.05)$ and vitreous incarceration $(F=5.80$, $P<0.05)$ were significant factors, and no other factors (age, axial length, or surgical time) were significant (Table 3 ).

Table I Baseline features of massage time

\begin{tabular}{|c|c|c|}
\hline & rRD & Macular disease \\
\hline Massage time at & $58.2 \pm 40.6(n=36)$ & $43.9 \pm 25.2(n=48)$ \\
\hline infusion sites (seconds) & (range I2-204) & (range 13-117) \\
\hline $\begin{array}{l}\text { Massage time at } \\
\text { manipulation sites } \\
\text { (seconds) }\end{array}$ & $\begin{array}{l}|33 .| \pm 83 . \mid(n=72) \\
\text { (range } \mid 2-378)\end{array}$ & $\begin{array}{l}60.5 \pm 44.4(n=96) \\
\text { (range 9-2I7) }\end{array}$ \\
\hline $\begin{array}{l}\text { Total massage time of } \\
\text { each case (seconds) }\end{array}$ & $\begin{array}{l}324.3 \pm 123.8(n=36) \\
\text { (range 103-604) }\end{array}$ & $\begin{array}{l}164.9 \pm 90.2(n=48) \\
\text { (range 66-469) }\end{array}$ \\
\hline
\end{tabular}

Abbreviation: rRD, rhegmatogenous retinal detachment.
Table 2 Baseline features of criterion variables

\begin{tabular}{lll}
\hline & rRD $(\mathbf{n}=\mathbf{3 6})$ & Macular disease $(\mathbf{n = 4 8})$ \\
\hline Age (years) & $53.2 \pm 11.2$ & $70.6 \pm 7.3$ \\
& $($ range 26-72) & $($ range 47-85) \\
Surgical time & $76.9 \pm 19.2$ & $40.7 \pm 12.9$ \\
(minutes) & $($ range 48-135) & $($ range 25-7I) \\
Axial length & $26.10 \pm 2.00$ & $24.10 \pm 2.30$ \\
(mm) & $($ range 22.90-30.58) & (range 20.93-31.46) \\
\hline
\end{tabular}

Abbreviation: $r R D$, rhegmatogenous retinal detachment.

In the analysis of infusion sites $(\mathrm{n}=84)$, only age $(F=9.89$, $P<0.05)$ was a significant factor, and no other factors (vitreous incarceration, axial length, or surgical time) were significant (Table 4). In the analysis of manipulation sites ( $\mathrm{n}=168)$, only vitreous incarceration $(F=8.81, P<0.05)$ was a significant factor, and no other factors (age, axial length, or surgical time) were significant (Table 5). No cases showed hypotony $(\leq 8 \mathrm{mmHg}$ ) on postoperative day 1 .

\section{Discussion}

\section{Intraocular manipulation}

Intraocular manipulation was considered to have influenced self-sealing of sclerotomy in 23-gauge TSV the most, because the $F$-value for intraocular manipulation was much greater than that for vitreous incarceration in the analysis of all sclerotomies. Lakhanpal et al commented that more extensive intraocular manipulation at the surgeon's dominant hand site probably caused wound extension, thus requiring suture placement. ${ }^{10}$ According to their paper, intraocular manipulation decreases the valve architecture of sclerotomy. In our study, the cannula at the infusion site was moved much less during surgery because no intraocular manipulation was applied. Therefore, little deformation of the sclerotomy existed at manipulation sites. However, intraocular manipulation, such as aiming the vitreous cutter, endolaser, and endoilluminator in multiple directions in the vitreous cavity, results in additional deformation of the sclerotomy. Restoring this extra deformation by scleral massage thus took a longer time. This is considered to be why intraocular manipulation was significant in the analysis of all sclerotomies.

Table 3 Statistical analysis of all sclerotomies $(n=252)$

\begin{tabular}{lll}
\hline Factor & F-value & $P$-value \\
\hline Age & 1.36 & 0.24 \\
Surgical time & 2.60 & 0.11 \\
Vitreous incarceration & 5.80 & $<0.05$ \\
Intraocular manipulation & 29.8 & $<0.05$ \\
Axial length & 0.03 & 0.87 \\
\hline
\end{tabular}


Table 4 Statistical analysis of infusion sites $(n=84)$

\begin{tabular}{lll}
\hline Factor & F-value & P-value \\
\hline Age & 9.89 & $<0.05$ \\
Surgical time & 0.90 & 0.34 \\
Vitreous incarceration & 0.99 & 0.32 \\
Axial length & 1.15 & 0.29 \\
\hline
\end{tabular}

\section{Vitreous incarceration}

The other factor that was significant in the analysis of all sclerotomies was vitreous incarceration, and this showed the same result in the analysis of manipulation sites. Vitreous incarceration may complement the restoration of valve architecture for self-sealing of sclerotomy performed with gas tamponade because the $F$-value for vitreous incarceration was less than the $F$-value for intraocular manipulation in the analysis of all sclerotomies. Byeon et al described wound configuration rather than incarceration of the vitreous tuft as potentially contributing to the self-sealing nature of sutureless sclerotomy, ${ }^{11}$ and that concept is in agreement with the present findings. However, self-sealing in infusion sites consisted only of restoring the valve architecture because vitreous incarceration was not a significant factor in the analysis of infusion sites. The small sclerotomy deformation due to the lack of intraocular manipulation resulted in little need for vitreous incarceration at the infusion sites.

\section{Age}

Age was significant only in the analysis of infusion sites. Because of the lack of intraocular manipulation and the limited need for vitreous incarceration at infusion sites, age became a more prominent factor influencing self-sealing of sclerotomy. Although age influenced self-sealing of sclerotomy, the lower degree of influence compared with intraocular manipulation and vitreous incarceration meant that age was insignificant in the analysis of all sclerotomies and in the analysis of manipulation sites. Friberg et al described a significant positive correlation between scleral stiffness and age, ${ }^{12}$ and Byeon et al stated that the more flexible sclera in younger patients might have resulted in incomplete closure of the sclerotomy sites, ${ }^{13}$ and that less rigid eyes might be

Table 5 Statistical analysis of manipulation sites $(n=168)$

\begin{tabular}{lll}
\hline Factor & $\boldsymbol{F}$-value & $\boldsymbol{P}$-value \\
\hline Age & 0.03 & 0.29 \\
Surgical time & 2.04 & 0.15 \\
Vitreous incarceration & 8.81 & $<0.05$ \\
Axial length & 0.03 & 0.85 \\
\hline
\end{tabular}

more prone to wound dehiscence or distortion of wound configuration. ${ }^{11}$ With moderate scleral stiffness, which increases with aging, the valve architecture would become easier to restore by scleral massage. For this reason, age would correlate with self-sealing of the sclerotomy in the examination of infusion sites.

\section{Surgical time}

Lin et al stated that surgical duration was related to leakage rates via tissue fatigue in 23 -gauge TSV. ${ }^{5}$ However, surgical time was not significant in our study, ie, the influence of surgical time on self-sealing was unclear. This might be due to the reduced influence of surgical time on self-sealing compared with intraocular manipulation, vitreous incarceration, and age.

\section{Axial length}

Axial length is reported to influence self-sealing of sclerotomy, because long axial length and myopia are associated with a thin sclera and deranged scleral collagen. ${ }^{14}$ Woo et al noted that the abnormal architecture of scleral tissue in myopic eyes could be associated with poor wound sealing and postoperative hypotony. ${ }^{15}$ However, like surgical time, no significant correlation between axial length and massage time was found in each analysis. The ratio of tunnel length to width in the sclerotomy of TSV is obviously greater than the ratio in cataract surgery. Sclerotomy in TSV can thus result in acquisition of a tunnel length sufficient for self-sealing. This is the reason for the lack of correlation between axial length and massage time in each analysis.

The present analysis has some limitations. First, we used massage time as a surrogate marker for degree of difficulty with self-sealing. However, massage time might not correspond perfectly with degree of difficulty of self-sealing, ie, surgeon bias could influence massage time. Having the same surgeon perform each surgery would minimize any such bias. On the other hand, because massage time in sutured sclerotomies and massage time in self-sealing sclerotomies were similarly dealt with in our analysis, little possibility of error in our analysis was present.

Second, we believe that no postoperative sclerotomy leakage had occurred, because no cases showed hypotony on postoperative day 1 . However, it is unclear whether selfsealing of sclerotomy remained complete after surgery, even if the sclerotomy was judged closed at the end of surgery. The reason for this is that postoperative hypotony could have existed several hours after the end of surgery even if no hypotony was seen on postoperative day $1 .{ }^{15}$ 
Third, intraoperative manipulation might not have been completely equal in each case. However, the differences in intraoperative manipulation at each manipulation site were slight compared with differences in intraocular manipulation between infusion site and manipulation site. We therefore regarded intraocular manipulation in this analysis as present for manipulation sites and not present for infusion sites.

Fourth, we did not perform the correct evaluation of vitreous incarceration using ultrasound biomicroscopy or endoscopy. Minimal peripheral vitrectomy was regarded as causing vitreous incarceration by remnant vitreous.

Fifth, intraocular pressure during scleral massage at the infusion site was checked by tactile examination, and thus would have introduced subjective inaccuracies according to the judgment of the surgeon. The impact of errors in massage time at the infusion site could not be ignored.

To conclude, in sclerotomy performed with gas tamponade using 23-gauge TSV, intraocular manipulation influenced self-sealing of sclerotomy the most, followed by vitreous incarceration and then age. The relative influence of other factors remains unclear. These findings suggest that self-sealing of sclerotomy involves restoring the valve architecture by scleral massage, and is complemented by vitreous incarceration.

\section{Disclosure}

The authors report no conflicts of interest in this work.

\section{References}

1. Fujii GY, De Juan E Jr, Humayun MS, et al. Initial experience using the transconjunctival sutureless vitrectomy system for vitreoretinal surgery. Ophthalmology. 2002;109(10):1814-1820.

2. Eckardt C. Transconjunctival sutureless 23-gauge vitrectomy. Retina. 2005;25(2):208-211.
3. Fine HF, Iranmanesh R, Iturralde D, Spaide RF. Outcomes of 77 consecutive cases of 23-gauge transconjunctival vitrectomy surgery for posterior segment disease. Ophthalmology. 2007;114(6):1197-1200.

4. Oshima Y, Kadonosono K, Yamaji H, et al; Japan Microincision Vitrectomy Surgery Study Group. Multicenter Survey with a systematic overview of acute-onset endophthalmitis after transconjunctival microincision vitrectomy surgery. Am J Ophthalmol. 2010;150(5):716-725.

5. Lin AL, Ghate DA, Robertson ZM, O'Sullivan PS, May WL, Chen CJ. Factors affecting wound leakage in 23-gauge sutureless pars plana vitrectomy. Retina. 2011;31(6):1101-1108.

6. Shimozono M, Oishi A, Kimakura H, Kimakura M, Kurimoto Y. Threestep incision for 23-gauge vitrectomy reduces postoperative hypotony compared with an oblique incision. Ophthalmic Surg Lasers Imaging. 2011;42(1):20-25.

7. Amato JE, Akduman L. Incidence of complications in 25-gauge transconjunctival sutureless vitrectomy based on the surgical indications. Ophthalmic Surg Lasers Imaging. 2007;38(2):100-102.

8. Shimada H, Nakashizuka H, Mori R, Mizutani Y. Expanded indications for 25-gauge transconjunctival vitrectomy. Jpn J Ophthalmol. 2005; 49(5):397-401.

9. Parolini B, Prigione G, Romanelli F, Cereda MG, Sartore M, Pertile G. Postoperative complications and intraocular pressure in 943 consecutive cases of 23-gauge transconjunctival pars plana vitrectomy with 1-year follow-up. Retina. 2010;30(1):107-111.

10. Lakhanpal RR, Humayun MS, De Juan E, et al. Outcomes of 140 consecutive cases of 25-gauge transconjunctival surgery for posterior segment disease. Ophthalmology. 2005;112(5):817-824.

11. Byeon SH, Lew YJ, Kim M, Kwon OW. Wound leakage and hypotony after 25-gauge sutureless vitrectomy: factors affecting postoperative intraocular pressure. Ophthalmic Surg Lasers Imaging. 2008; 39(2):94-99.

12. Friberg TR, Lace JW. A comparison of the elastic properties of human choroid and sclera. Exp Eye Res. 1988;47(3):429-436.

13. Byeon SH, Chu YK, Lee SC, Koh HJ, Kim OW, Kwon OW. Problems associated with the 25-gauge transconjunctival sutureless vitrectomy system during and after surgery. Ophthalmologica. 2006;220(4): 259-265.

14. Curtin BJ, Iwamoto T, Renaldo DP. Normal and staphylomatous sclera of high myopia. An electron microscopic study. Arch Ophthalmol. 1979;97(5):912-915.

15. Woo SJ, Park KH, Hwang JM, Kim JH, Yu YS, Chung H. Risk factors associated with sclerotomy leakage and postoperative hypotony after 23-gauge transconjunctival sutureless vitrectomy. Retina. 2009; 29(4):456-463.
Clinical Ophthalmology

\section{Publish your work in this journal}

Clinical Ophthalmology is an international, peer-reviewed journal covering all subspecialties within ophthalmology. Key topics include: Optometry; Visual science; Pharmacology and drug therapy in eye diseases; Basic Sciences; Primary and Secondary eye care; Patient Safety and Quality of Care Improvements. This journal is indexed on Submit your manuscript here: http://www.dovepress.com/clinical-ophthalmology-journal

\section{Dovepress}

PubMed Central and CAS, and is the official journal of The Society of Clinical Ophthalmology (SCO). The manuscript management system is completely online and includes a very quick and fair peer-review system, which is all easy to use. Visit http://www.dovepress.com/ testimonials.php to read real quotes from published authors. 